\title{
Evidence of Allergic Reactions and Cardiopulmonary Impairments among Traders Operating from Foodstuff Warehouses
}

\author{
Sam Ibeneme, ${ }^{1,2,3}$ Viola Egbosionu, ${ }^{1}$ Georgian Ibeneme, ${ }^{4}$ Amarachi Ezuma, ${ }^{2,5}$ \\ Theresa Ettu, ${ }^{6}$ Joseph Nwankwo, ${ }^{7}$ Dnyanesh Limaye, ${ }^{3,8}$ and Emmanuel Nna ${ }^{9}$ \\ ${ }^{1}$ Department of Medical Rehabilitation, Faculty of Health Sciences, College of Medicine, University of Nigeria, \\ Enugu Campus, Enugu, Nigeria \\ ${ }^{2}$ Clinical Trial Consortium University of Nigeria, Nsukka, Nigeria \\ ${ }^{3}$ UNIRED Research Group, Hochschule Hannover (University of Applied Sciences and Arts), Hannover, Germany \\ ${ }^{4}$ Department of Nursing Sciences, Faculty of Health Sciences \& Technology, College of Medicine, University of Nigeria, \\ Enugu Campus, Abakaliki, Ebonyi State, Nigeria \\ ${ }^{5}$ Department of Physiotherapy, University of Nigeria Teaching Hospital, Ituku/Ozalla, Enugu, Nigeria \\ ${ }^{6}$ National Open University of Nigeria, Owerri Study Centre, Owerri, Imo State, Nigeria \\ ${ }^{7}$ Department of Medical Rehabilitation, Faculty of Health Sciences, Nnamdi Azikiwe University, Nnewi Campus, \\ Anambra State, Nigeria \\ ${ }^{8}$ German UNESCO Unit on Bioethics, Fakultät III-Medien, Information und Design, Hochschule Hannover \\ (University of Applied Sciences and Arts), Hannover, Germany \\ ${ }^{9}$ Safety Molecular Laboratory, Rangers Avenue, Independence Layout, Enugu, Nigeria
}

Correspondence should be addressed to Sam Ibeneme; sam.ibeneme@extern.hs-hannover.de

Received 26 October 2016; Revised 19 November 2016; Accepted 24 November 2016

Academic Editor: Nikolaos Siafakas

Copyright (C) 2016 Sam Ibeneme et al. This is an open access article distributed under the Creative Commons Attribution License, which permits unrestricted use, distribution, and reproduction in any medium, provided the original work is properly cited.

Background. Foodstuff traders operating from warehouses (FTFW) are potentially exposed to dangerous rodenticides/pesticides that may have adverse effects on cardiopulmonary function. Methods. Fifty consenting male foodstuff traders, comprising 15 traders (21-63 years) operating outside warehouses and 35 FTFW (20-64 years), were randomly recruited at Ogbete Market, Enugu, in a cross-sectional observational study of spirometric and electrocardiographic parameters. Seventeen FTFW (21-57 years) participated in focus group discussions. Qualitative and quantitative data were analysed thematically and with independent $t$-test and Pearson correlation coefficient at $p<0.05$, respectively. Results. Most FTFW experienced respiratory symptoms, especially dry cough (97.1\%) and wheezing (31.4\%) with significant reductions in forced vital capacity (FVC) $(t=-2.654 ; p=0.011)$, forced expiratory volume in one second $\left(\mathrm{FEV}_{1}\right)(t=-2.240 ; p=0.030)$, maximum expiratory flow rate $\left(\mathrm{FEF}_{200-1200}\right)(t=-1.148$; $p=-0.047)$, and forced end-expiratory flow $\left(\mathrm{FEF}_{25-75}\right)(t=-1.11 ; p=0.007)$. The maximum mid-expiratory flow $\left(\mathrm{FEF}_{25-75}\right)$ was marginally decreased $(p>0.05)$ with a significantly prolonged $(p<0.05)$ QTc interval. Conclusion. Allergic response was evident in the FTFW. Significant decrease in FVC may negatively impact lung flow rates and explains the marginal decrease in $\mathrm{FEF}_{25-75}$, which implies a relative limitation in airflow of peripheral/distal airways and elastic recoil of the lungs. This is consistent with obstructive pulmonary disease; a significant decrease in $\mathrm{FEF}_{75-85} / \mathrm{FEV}_{1}$ supports this conclusion. Significant decrease in $\mathrm{FEF}_{200-1200}$ indicates abnormalities in the large airways/larynx just as significantly prolonged ventricular repolarization suggests cardiac arrhythmias.

\section{Introduction}

In Nigeria, most subsistence farmers are foodstuff traders who prefer to operate from foodstuff warehouses rather than open market. This is because the common feature of the foodstuff warehouses is lack of windows, vents, or other openings to minimize points of entry of rodents/pests. Like most buildings in Nigeria, the foodstuff warehouses 
are poorly ventilated, and this practice persists, because of noncompliance to standard building codes [1]. Apparently, the traders are not sufficiently informed on the risks associated with inhalation of grain dusts and organic and inorganic chemical agents in pesticides/rodenticides often used in foodstuff warehouses. Some of these pesticides have been detected in grains/vegetables $[2,3]$ and are oftentimes misused due to nonadherence to caution, which might be common among illiterates. In fact, there is a correlation between high levels of occupational exposure to pesticides and low educational levels [4], probably due to their inability to read and adhere to hazard warnings found on each pack. Improper use of pesticides in developing countries has been reported, which included use of banned pesticides [5], lack of self-protection [6], overspraying [7], improper handling of pesticide containers [8], and, even, reuse of washed pesticide containers as containers for food and drinking water by $35.4 \%$ and $77.2 \%$ of farmers in Nigeria and Ethiopia, respectively [9]. Potential health hazards include pesticide self-poisoning [10], which is a major public health problem resulting in 3 million cases of acute poisoning, and 250 to 370,000 deaths, annually $[11,12]$. However, much attention has not been focused on the likely cardiopulmonary dangers that may arise when traders operate from poorly ventilated foodstuff warehouses, where rodenticides/pesticides are regularly applied.

The acute health consequences of inappropriate uses of rodenticides/insecticides/chemicals in foodstuff preservation are well documented, ranging from increased prevalence of respiratory symptoms, lung dysfunction, and cardiopulmonary morbidity to and mortality [13]. This is possible, because the respiratory tract has direct contact with the environment and is often the site of injury from occupational exposure to airborne noxious pollutants $[14,15]$. Ordinarily, exposure to dust has long been associated with the prevalence of varying degrees of allergy, cough, chronic bronchitis, sneezing, eye irritation, infection of the throat, airway obstruction, and respiratory symptoms in human populations $[6,16]$. In addition, environmental assessment of grain factories and warehouses showed the presence of biologically active endotoxins [17]. The gram negative bacterial endotoxins can provoke intense immunotoxic and immunomodulating effects in vitro and in vivo [18-20] and thus can aggravate adverse pulmonary responses to grain dust. Dust from rice husk causes damage to bronchial passages, along with damage to the elastic component of alveolar walls [21], and also contains some air borne endotoxins which cause inflammatory reactions in broncopulmonary system. Air-borne endotoxin is commonly present in areas where cotton is produced and stored [21]. In a poorly ventilated environment, it is possible that these adverse changes might be worsened due to sustained inhalation of accumulated pollutants in ambient air.

Considering their poor level of education, it is expected that most local traders operating from foodstuff warehouses may not take appropriate protective measures to avoid inhalation of noxious substances or might misuse pesticides/chemicals available for foodstuff preservation, which may predispose them to life-threatening/health-related complications. This is reasonable, because other studies have associated the misuse of such dangerous chemicals with such factors as perceptions [22, 23] and ignorance/level of knowledge, advice of pesticide retailers [24], planting season, and cultural factors [25] among others.

Evidence of ventilatory impairments can be determined using spirometric tests [26] yet such studies have not been done among foodstuff traders in Nigeria, where this population are occupationally exposed to grain dust in poorly ventilated warehouses/shops. The immediate and long term health outlook, for this population, is worrisome considering that acute and chronic respiratory effects on exposure to grain dust include such responses as Farmer's Lung [27], Grain Fever Syndrome [28], chronic bronchitis [29], and asthma [30]. Indeed, without a sufficient understanding of the risks involved, the exposed may not take appropriate protective measures, leading most likely to unfavorable health-related outcomes [31].

\section{Methods}

2.1. Population and Study Design. A descriptive, crosssectional survey design was used to study the symptoms of allergy and cardiopulmonary function in traders who operated from foodstuff warehouses within Akwata Ogbete Main Market, Enugu. Ogbete Main Market was selected for the study, because it is the major foodstuff market in Enugu metropolis, Enugu State, Nigeria.

Recruitment for the study was conducted at the market. Using the power analysis of $80 \%$ to detect a difference between means of 0.46 , with significance level (alpha) of 0.05 (one-tailed), a sample size of 55 was mathematically determined. This was calculated using GraphPad prism software (StatMate version 2.0). However, out of 123 foodstuff traders in the market, only 50 consenting participants met the selection criteria, comprising 35 traders who operated from foodstuff warehouses and 15 traders who operated from open market (i.e., outside the warehouses). The participants were selected using stratified sampling techniques, while providing for almost equal representation for traders of three major grain foodstuffs: rice, beans, and maize. The study process involved four stages: obtaining informed consent, administering the questionnaire, conducting verbal interviews, and cardiopulmonary tests. The test instrument was the National Institute for Occupational Safety and Health Asthma Identification Project Questionnaire 1996 [32] and consists of 3 main sections that assess body anthropometry, workplace experience, medical history, and symptoms of respiratory dysfunction, including nature of symptoms, onset of symptoms, frequency of symptoms, and severity of symptoms. This questionnaire has been validated as indicated in the literature [33].

2.2. Data Collection. The researchers had the permission of the Ogbete Market union leaders to approach and recruit consenting foodstuff traders immediately after a health talk at their weekly meeting. With the test instrument, information was elicited from the participants and then entered and verified by the researchers after further questioning during the verbal interview. Three inclusion criteria were applied as follows: (1) foodstuff traders who operate from either open 
market or warehouse at Akwata Main Market Enugu, (2) age range of 20 to 64 years, and (3) traders who have $>2$ years of business experience at their current location. The test instrument was administered to all those who met the selection criteria. The participants were categorized into 2, namely, (i) traders who operated from foodstuff warehouses and (ii) traders who operated from open market. The participants were interviewed after which their cardiopulmonary assessment was done.

The traders were instructed on the required spirometric test procedures, after demonstrations of the tests were performed by the researchers to ensure that the participants were fully acquainted with the procedures. All constricting clothing was loosened to prevent alteration of test results from restricted thoracic expansion and abdominal mobility. Each participant sat in an upright position to carry out the breathing protocol (Morris/Polgar formula) in the following steps: (a) breath in and out three times in a relaxed position, (b) breath in as much as possible (TLC level), (c) breath out as fast and as much as possible (forced expiration), and (d) breath in as fast and as much as possible (forced inspiration). Thereafter, the peak expiratory flow rate (PEFR), forced vital capacity (FVC), and forced expiratory volume at the first second $\left(\mathrm{FEV}_{1}\right)$ were measured. The protocol was repeated three times, and the highest value, with less than $5 \%$ deviation from the other readings, was used for further calculations to determine the pulmonary function according to the standards proposed by the American Thoracic Society (ATS) [34]. Subsequently, the forced expiratory volume in one second, as a percentage of the forced vital capacity $\left(\mathrm{FEV}_{1} \%\right)$, was determined from the values of FVC and $\mathrm{FEV}_{1}$. Also, the electrocardiogram (using ECG 12 channel with Spirometer) recording was done after imputing the subjects' biodata (code number, age, weight, height, and race) into the device. Thereafter, the participants were requested to comfortably lie on a couch and in supine position. Specific parts of the body were cleaned using an alcohol disinfectant prior to electrode placement, which were positioned as follows: V1, fourth intercostal space, right sternal border; V2, fourth intercostal space, left sternal border; V3, midway between V2 and V4; V4, fifth intercostal space, left midclavicular line; V5, level with V4, left anterior axillary line; V6, level with V4, left mid axillary line. The appropriate colours of the electrodes were used and matched the following locations: right arm (red), left arm (yellow), left leg (green), and right leg (black). The leads for the ECG were connected to the attached electrodes, and the evoked electrical potentials were monitored, measured, and displayed on the LCD screen of the device, after which it was printed from the device.

To provide an in-depth understanding of the experience of foodstuff traders who operated from warehouses, further information on foodstuff preservation practices, ventilation of warehouses, awareness of symptoms of allergy, and implications for health was explored in focus group discussions (FGDs). The FGDs involved 17 of the 35 traders who operated from warehouses, who were selected using purposive sampling technique, with an age range of 2263 years. Three FGDs were held with 5-6 traders, each lasting for 40-45 minutes. Verbatim responses from the

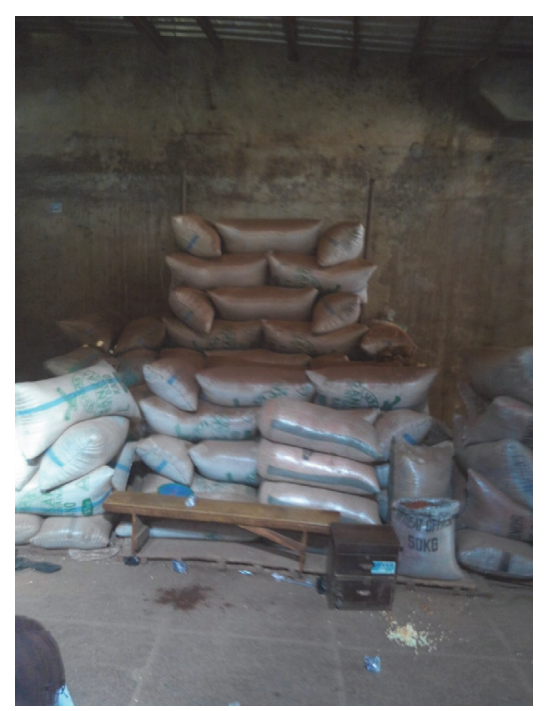

FIGURE 1: A typical foodstuff warehouse showing the roof without vents.

FGDs were transcribed and categorized into different themes, including traders' views on whether foodstuff preservation practices, warehouse design, ventilation, and usage affect their respiratory function.

2.3. Statistical Analysis. Qualitative data were analyzed thematically, while quantitative data were analyzed using descriptive and inferential statistics including independent $t$-test to determine the statistical difference between the means of the variables and Pearson correlation coefficient to determine the relationship between the variables. Alpha was set at $p<0.05$.

\section{Results}

The participants comprised 15 male foodstuff traders who operated from open market (i.e., outside warehouses/control group) with an age range of 21-63 years and 35 male traders who operated from the warehouses (test group) with an age range of 20-64 years.

Almost all (34/97.1\%) the foodstuff traders who operated from warehouses (Figures 1 and 2) had symptoms of cough (Table 1). Other respiratory symptoms recorded among this group were in the following descending order: wheezing $(11 / 31.4 \%)$, chest tightness $(9 / 25.7 \%)$, and dyspnea $(8 / 22.8 \%)$. However, the greatest number $(5 / 33.33 \%)$ of foodstuff traders who operated from the open market (Figure 3) had chest tightness, with other respiratory symptoms in the following descending order: cough (4/26.67\%), dyspnea (3/20\%), and wheezing (2/13.33\%). In addition, there was a significant reduction $(p<0.05)$ in the $\mathrm{FVC}$ and $\mathrm{FEV}_{1}$ among the foodstuff traders who operated from warehouses compared to those that operated from the open market (Table 2) as well as a marginal reduction in PEFR $(p>0.05)$. The ECG (Table 3) showed evidence of prolonged PR-interval and QRS duration, respectively, as well as an increase in heart rate 


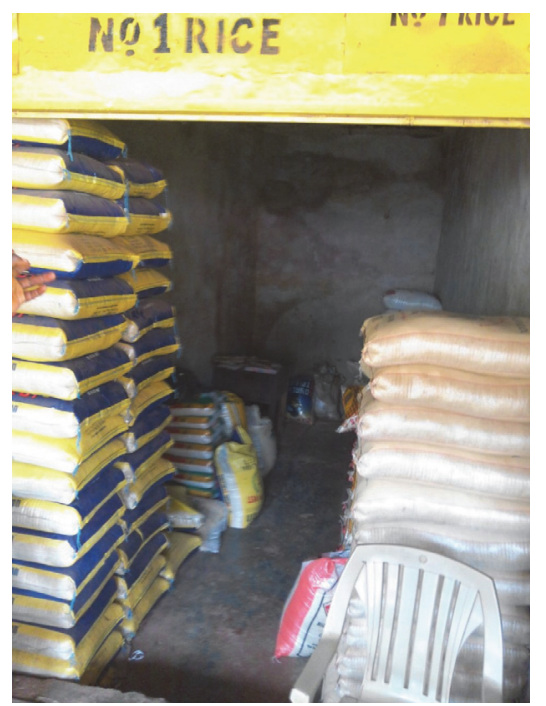

FIGURE 2: A foodstuff warehouse showing walls without windows.

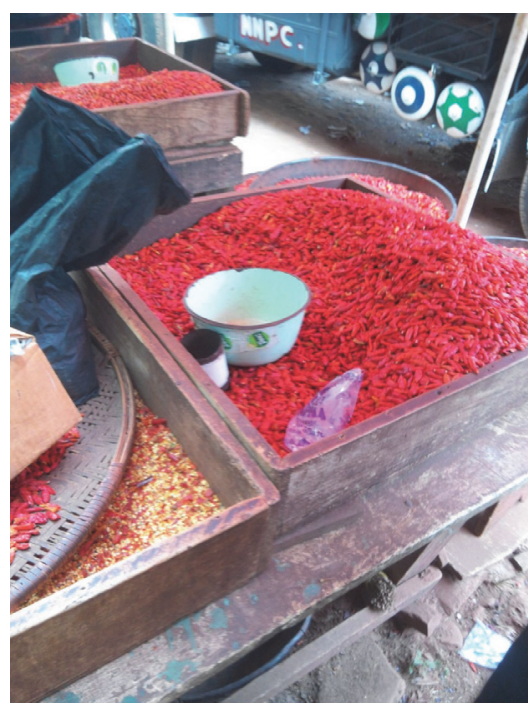

FIGURE 3: A foodstuff stall in open market.

among traders who operated from the warehouses compared to those that operated from the open market, though the difference in mean was not significant $(p>0.05)$. In contrast, a significantly prolonged $(p<0.05)$ QTc interval was observed among the foodstuff traders who operated from warehouses compared to those that operated from the open market.

Among traders who operated from foodstuff warehouses, FVC, $\mathrm{FEF}_{20-1200}, \mathrm{FEF}_{25-75}$, and $\mathrm{FEF}_{25}$ showed a significant negative relationship with the duration of exposure to grain/ foodstuff dust, respectively (Table 4). In contrast there was no significant relationship between the duration of exposure to grain/foodstuff dust and FEV1/FVC, PEFR, $\mathrm{FEF}_{75-85}$, and $\mathrm{FEV}_{1}$ among traders who operated from foodstuff warehouses. There was a significant $(p<0.05)$ positive relationship between the duration of exposure to foodstuff dust
TABLE 1: Profile of cardiopulmonary symptoms observed among foodstuff traders who operated from warehouses $(N=35)$ and open market $(N=15)$

\begin{tabular}{lcc}
\hline $\begin{array}{l}\text { Respiratory } \\
\text { symptoms }\end{array}$ & $\begin{array}{c}\text { Warehouse } \\
\text { traders } \\
(N=35)\end{array}$ & $\begin{array}{c}\text { Open market } \\
\text { traders } \\
(N=15)\end{array}$ \\
\hline $\begin{array}{l}\text { Wheezing } \\
\text { Dyspnea } \\
\text { Chest }\end{array}$ & $11(31.4 \%)$ & $2(13.33 \%)$ \\
tightness & $8(22.8 \%)$ & $3(20 \%)$ \\
Cough & $9(25.7 \%)$ & $5(33.33 \%)$ \\
\hline
\end{tabular}

TABLE 2: Profile of lung function among foodstuff traders who operated from warehouses $(N=35)$ and open market $(N=15)$.

\begin{tabular}{|c|c|c|c|c|c|}
\hline Variables & Mean & SD & $\begin{array}{c}\text { Mean } \\
\text { difference }\end{array}$ & $t$-value & $p$ value \\
\hline \multicolumn{6}{|l|}{ FVC } \\
\hline (i) $\mathrm{WT}$ & 1.67 & 0.988 & \multirow{2}{*}{-0.723} & \multirow{2}{*}{-2.654} & \multirow{2}{*}{$0.011^{*}$} \\
\hline (ii) $\mathrm{OT}$ & 2.39 & 0.547 & & & \\
\hline \multicolumn{6}{|l|}{$\mathrm{FEV}_{1}$} \\
\hline (i) $\mathrm{WT}$ & 1.26 & 0.771 & \multirow{2}{*}{-0.497} & \multirow{2}{*}{-2.240} & \multirow{2}{*}{$0.030^{*}$} \\
\hline (ii) $\mathrm{OT}$ & 1.75 & 0.574 & & & \\
\hline \multicolumn{6}{|l|}{$\mathrm{FEV}_{1} / \mathrm{FVC}$} \\
\hline (i) $\mathrm{WT}$ & 81.94 & 25.722 & \multirow{2}{*}{4.890} & \multirow{2}{*}{0.663} & \multirow{2}{*}{0.510} \\
\hline (ii) $\mathrm{OT}$ & 77.05 & 18.737 & & & \\
\hline \multicolumn{6}{|c|}{ FEF200-1200 } \\
\hline (i) $\mathrm{WT}$ & 1.84 & 1.053 & \multirow{2}{*}{-0.341} & \multirow{2}{*}{-1.148} & \multirow{2}{*}{0.047} \\
\hline (ii) $\mathrm{OT}$ & 2.18 & 0.699 & & & \\
\hline \multicolumn{6}{|l|}{ FEF25-75 } \\
\hline (i) $\mathrm{WT}$ & 1.82 & 1.045 & \multirow{2}{*}{-0.261} & \multirow{2}{*}{-0.890} & \multirow{2}{*}{0.065} \\
\hline (ii) $\mathrm{OT}$ & 2.08 & 0.658 & & & \\
\hline \multicolumn{6}{|l|}{ FEF75-85 } \\
\hline (i) $\mathrm{WT}$ & 1.39 & 0.728 & \multirow{2}{*}{-0.221} & \multirow{2}{*}{-1.117} & \multirow{2}{*}{$-0.007^{*}$} \\
\hline (ii) $\mathrm{OT}$ & 1.61 & 0.344 & & & \\
\hline \multicolumn{6}{|l|}{ FEF25 } \\
\hline (i) $\mathrm{WT}$ & 1.90 & 1.136 & \multirow{2}{*}{-0.569} & \multirow{2}{*}{-1.726} & \multirow{2}{*}{-0.249} \\
\hline (ii) $\mathrm{OT}$ & 2.47 & 0.884 & & & \\
\hline \multicolumn{6}{|l|}{ FEF50 } \\
\hline (i) $\mathrm{WT}$ & 1.91 & 1.085 & \multirow{2}{*}{-0.242} & \multirow{2}{*}{-3.958} & $0.001^{*}$ \\
\hline (ii) $\mathrm{OT}$ & 2.15 & 0.688 & & & 0.001 \\
\hline FEF75 & & & & & \\
\hline (i) $\mathrm{WT}$ & 1.56 & 0.866 & -0.21 & -0.915 & $0.041^{*}$ \\
\hline (ii) $\mathrm{OT}$ & 1.78 & 0.444 & -0.21 & -0.915 & 0.041 \\
\hline PEF & & & & & \\
\hline (i) $\mathrm{WT}$ & 2.22 & 1.139 & -0.457 & -1.401 & 0.168 \\
\hline (ii) $\mathrm{OT}$ & 2.68 & 0.825 & & & \\
\hline
\end{tabular}

* indicates significance at $p<0.05$; WT: warehouse foodstuff traders; OT: open market foodstuff traders.

and QT interval among traders who operated from foodstuff warehouses (Table 5). Also, PR-int and QRS recorded showed 
TABLE 3: Electrocardiographic profile of traders who operated from foodstuff warehouses $(N=35)$ and open market $(N=15)$.

\begin{tabular}{cccccc}
\hline Variables & Mean & SD & Mean difference & $t$-value & $p$ value \\
\hline $\begin{array}{c}\text { Heart rate } \\
\text { (i) WT }\end{array}$ & 71.86 & 9.249 & 5.457 & 1.926 & 0.060 \\
(ii) OT & 66.40 & 9.022 & & & \\
PR-INT & & & & & \\
(i) WT & 169.31 & 25.649 & 12.181 & 1.616 & 0.113 \\
(ii) OT & 157.13 & 21.142 & & & \\
QRS DUR & & & & & \\
(i) WT & 83.77 & 14.355 & \multirow{2}{*}{5.305} & 1.333 & 0.189 \\
(ii) OT & 78.47 & 8.357 & & & \\
QTc & & & & & \\
(i) WT & 407.51 & 24.657 & 21.048 & 3.134 & $0.003^{*}$ \\
(ii) OT & 386.47 & 12.153 & & & \\
\hline
\end{tabular}

* indicates significance at $p<0.05$; WT: warehouse foodstuff traders; OT: open market foodstuff traders.

a significant $(p<0.05)$ negative relationship with $\mathrm{FEV}_{1}$, respectively (Table 6).

3.1. Focus Group Discussions. There were 17 participants for the FGDs, with an age range of 21 to 57 years. Most of the participants stated that the reasons why they operated from foodstuff warehouse included need to preserve their food stock from rodents/pests, and in appropriate moisture content, prevent loss of market and food value of their stock, ensure prompt access to food stock by their customers, make up for inadequate number of stalls in the open market, and reduce overhead cost of foodstuff preservation. The traders agreed that they faced a lot of challenges while operating from warehouses that included poor visibility, stuffy environment/poor ventilation $n$, absence of basic municipal services, and bodily discomfort after inhalation of grain dusts and pesticides/rodenticides. One trader stated that

nowadays, we use a lot of chemicals ... to check
attack (infestation) by rodents...,., unlike before,
when we set bobby traps for them. ... recent
outbreaks of Lassa fever in neighbouring states,
were linked to rats...we may not know if rats also
cause (transmit) Ebola ...we are really scared to
set manual/bobby traps for rats or touch rats when
our traps catch them.

Some other traders felt that the use of chemicals for food preservation predates the advent of Lassa fever and Ebola outbreaks, which they also recognized as a major factor in their preference for rodenticides/insecticides compared to previously preferred traditional methods. Some of the traditional preservatives, which they still used in addition to rodenticides/pesticides, included pepper, oil, ashes of certain types of woods, animal droppings, certain dry herbs, and frightening human effigies. Another trader said that he was satisfied with the results he got when he used rodenticides/insecticides, which he personally applied. $\mathrm{He}$ stated when I started this business newly, I relocated from Northern Nigeria where rodents were fewer unlike South eastern Nigeria; and incurred losses from rodents that destroyed most of my food stock...on numerous occasions. I sought the advice of more experienced traders, who recommended certain rodenticides/pesticides...After I had applied them, I observed they killed quite a number of rats the next day... since then, I have never looked back (never hesitated) to apply these rodenticides....

While some of the traders stated that the local government agricultural officers occasionally came to spray pesticides/rodenticides in the warehouses, some others said that such visits were not regular and timely; hence they resorted to applying rodenticides/pesticides by themselves. Nevertheless, they agreed that they do not know either the constituents of the rodenticides/pesticides or quantity of the chemicals that would be effective but guessed that the bigger the quantity is, the more effective the results will be. One trader stated

I normally applied large quantities of the rodenticides/pesticides depending on the type of pests/rodents and the season ... for instance, in rainy season, I preferred to use chemical dusts than aerosols or liquid chemical agents so that the whole place is not damp...unlike in dry season when the reverse is the case.

Most of the traders agreed that they do not wear any protective gears when they applied these chemicals but made sure they washed their hands to avoid ingesting the chemical residues on their hands. However, some others disagreed with this practice and agreed that there is a need for protective gears when applying such chemicals, especially considering the effects of such chemicals when inhaled, which may be worse when there is a bodily contact. Another trader said

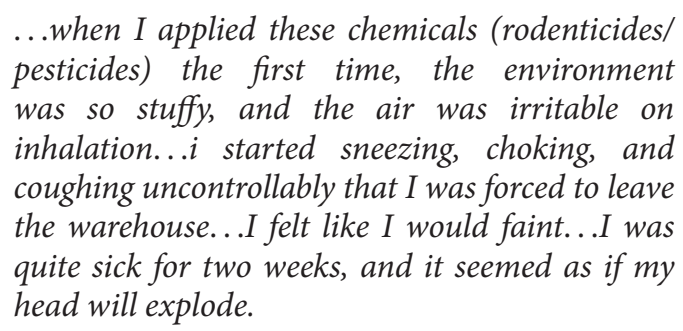

Most of the traders shared similar experiences and recounted the many side effects associated with exposure or use of rodenticides/pesticides in foodstuff warehouses to include general feelings of malaise, low grade fever, flu-like symptoms, sneezing, choking, catarrh, headaches, sore throat, eye irritation, palpitation, flutters, chest tightness, shallow breathing, cold sweat, dry cough, skin rashes, weakness, and difficulty in breathing. Despite observing some side effects after exposure to pesticides/rodenticides in the warehouses, the traders were not aware of health risks associated with the use of such pesticides/rodenticides. Some of them felt that they are physically strong enough and found no need to stay away from their goods when pesticides/rodenticides are 
TABLE 4: Relationship between duration of occupational exposure to airborne pollutants and lung function among traders $(N=35)$ that operated from warehouses.

\begin{tabular}{lcccccccc}
\hline Lung function & $\mathrm{FVC}$ & $\mathrm{FEV1}$ & $\mathrm{FEV}_{1} / \mathrm{FVC}$ & $\mathrm{FEF}_{200-1200}$ & $\mathrm{FEF}_{25-75}$ & $\mathrm{FEF}_{75-85}$ & $\mathrm{PEF}$ & $\mathrm{FEF}_{25}$ \\
\hline & $r=-0.38$ & $r=-0.23$ & $r=0.28$ & $r=-0.35$ & $r=-0.35$ & $r=-0.24$ & $r=0.29$ & $r=-0.36$ \\
Duration of exposure (years) & $p=0.02^{*}$ & $p=0.19$ & $p=0.10$ & $p=0.03^{*}$ & $p=0.04^{*}$ & $p=0.17$ & $p=0.08$ & $p=0.03^{*}$ \\
& $r^{2}=0.1444$ & $r^{2}=0.0529$ & $r^{2}=0.0784$ & $r^{2}=0.1225$ & $r^{2}=0.1225$ & $r^{2}=0.0576$ & $r^{2}=0.0841$ & $r^{2}=0.1296$ \\
\hline
\end{tabular}

* indicates significance at $p<0.05$.

TABLE 5: Relationship between duration of occupational exposure to airborne pollutants and electrical activity of the heart among traders $(N=35)$ that operated from warehouses.

\begin{tabular}{lcccccccc}
\hline Electrical activity & HR & PR-INT & QRS & P-AXIS & R-AXIS & T-AXIS & QT & QTc \\
\hline \multirow{2}{*}{ Duration of exposure (years) } & $r=0.22$ & $r=-0.09$ & $r=0.08$ & $r=-0.05$ & $r=-0.30$ & $r=-0.28$ & $r=0.41$ & $r=0.12$ \\
& $p=0.21$ & $p=0.61$ & $p=0.63$ & $p=0.77$ & $p=0.081$ & $p=0.10$ & $p=0.02^{*}$ & $p=0.51$ \\
\hline
\end{tabular}

* indicates significance at $p<0.05$.

TABLE 6: Relationship between lung function and electrical activity of the heart among traders $(N=35)$ that operated from warehouses.

\begin{tabular}{lcccc}
\hline Lung function & FVC $(r / p)$ & FEV $_{1}(r / p)$ & PEF $(r / p)$ & FEV $_{1} / \mathrm{FVC}(r / p)$ \\
\hline HR & $0.255(0.139)$ & $0.070(0.691)$ & $0.064(0.714)$ & $-0.322(0.059)$ \\
PR int & $-0.160(0.358)$ & $-0.349(0.040)^{*}$ & $-0.066(0.707)$ & $-0.077(0.0661)$ \\
QRS & $-0.324(0.057)$ & $-0.356(0.036)^{*}$ & $-0.172(0.323)$ & $-0.051(0.0796)$ \\
QTc & $-0.190(0.273)$ & $-0.423(0.11)$ & $-0.109(0.533)$ & $-0.060(0.734)$ \\
\hline
\end{tabular}

$(r / p)$ indicates the following: $r$, Pearson correlation coefficient, and $p, p$ value; $*$ indicates significance at $p<0.05$.

applied. Most of them felt that these symptoms resolved after taking some medications but reoccurred severally each time they came to work at the warehouses. They expressed the view that these side effects persisted, because of poor ventilation of the warehouses, which were designed to have only one entrance in order to minimize entry points of pest/rodents into the facility. Most of them preferred that they remained in poorly ventilated warehouses than have rodents/pests destroy their investment/goods. A trader stated

\begin{abstract}
I know that breathing this bad air (inhalation of pollutants) is not good for my health...especially, when there are no openings for air circulation (ventilation) within this warehouse. However, we prefer to operate from the warehouses than open market stalls in order to minimize damage to our goods from pests and rodents...It is better to be rich while operating from this warehouse than to be poor while operating from the open market.
\end{abstract}

\section{Discussion}

Observation of dry cough (apart from other symptoms) by almost all the foodstuff traders who operated from warehouses suggests possibilities of allergic response. This was validated in the FGDs as the traders who operated from warehouses stated that immediately they were exposed to grain dust and other pollutants in the warehouses, they started sneezing and choking and had sore throat, low grade fever, rashes, malaise, catarrh, difficulty in breathing, cough, and other symptoms which are typical of allergic responses. Similar findings have been observed in some studies. For instance, Razlan et al. [35] reported and grouped the respiratory symptoms observed in rice mill workers into four main categories, namely, morning cough, morning cough with phlegm, chest tightness, and shortness of breath, of which chest tightness was the most common symptom (34.9\%), followed by morning phlegm (31.7\%), shortness of breath $(31.7 \%)$, and morning cough $(19.0 \%)$. Mostafa et al. [36] and Nku et al. [37] found a similar trend among street sweepers where the commonest respiratory symptom included cough, which they attributed to inhalation of dust from paved roads, a complex mixture of soil dust, deposited motor vehicle exhaust particles, tyre dust, brake lining wear dust, plant fragments, and other biological materials. In like manner, inhalation of dust of organic, inorganic, or chemical nature in foodstuff warehouses could elicit similar allergic symptoms and has the potential to irritate the respiratory tracts and trigger inflammatory processes that might result in allergic cough [38]. It is possible that subsequent and consistent occupational exposure will likely aggravate the established respiratory allergy and other pulmonary diseases, which might explain the findings of this study.

Since lower number of foodstuff traders who operated from open market had similar respiratory symptoms compared to traders who operated from warehouses, then it is plausible that proper ventilation might mitigate the adverse occupational exposure to inhaled allergens common with traders who operated from warehouses. Therefore, proper ventilation or lack of it would have played some important roles in the induction of allergic responses and consequent respiratory symptoms.

The relationship between housing and respiratory health has not been fully elucidated [39], but some studies suggest 
an association between damp or moldy indoor environments and respiratory difficulties [40,41]. In fact, it has been observed that environmental contaminants in combination with poor ventilation produce adverse health reactions [38] similar to what was observed among foodstuff traders who operated from warehouses. In contrast, Frankel et al. [41] reported that a higher ventilation rate may result to reduced exposure to inflammatory microbial constituents detected in a granulocyte assay. Therefore, it is possible that poor ventilation of buildings (houses/shops/warehouses), which has been reported in Nigeria [42-44], would have adversely contributed to the respiratory symptoms observed among foodstuff traders who operated from warehouses in this study. This view was validated in FGDs, where most of the traders stated that the warehouses from which they operated had no windows or mechanical ventilators for reasons that included minimizing all entry points for rodents and pests. However, most of them were unaware that molds and fungi can thrive in such humid environments, which will adversely affect respiratory health of occupants. For this reasons, they mainly attributed the respiratory symptoms they experienced to inhalation of rodenticides, pesticides, and dust from foodstuff (including organic and inorganic foodstuff preservatives).

4.1. Strength and Limitations of study. Airflow obstruction in asthma is known to deteriorate at the night and early morning, so lung function indices obtained during work hours, as was done in this study, may not accurately reflect variability. However, since this is a community-based study, there was a need to assess the participants within the market community and take inventory of their relevant experiences that might improve our understanding of the investigated phenomenon in that context. Furthermore, when spirometry is normal in persons with suspected asthma, a reasonable substitute is to provide a peak flow meter and guidelines to record the best of three readings twice a day, when symptoms occur and if necessary in combination with a probationary of treatment. This should be followed by an assessment, a few weeks later. However, this was not done, because the cross-sectional study design does not allow for a baseline measurement and subsequent follow-up. Moreover, some of the tests, including ECG, require training, experience, and good clinical skills to generate reliable results, which the participants commonly lack. The sample size was also small, since only consenting participants that met the selection criteria were studied. However, this was an observational study; and the intent was not to test hypotheses in order to establish causal relationships that link changes in cardiopulmonary parameters to exposure of the study population to grain dusts and pollutants. Rather it was intended to gain fuller insight into the experiences of the participants about the nature of cardiopulmonary changes likely to arise when exposed to grain dust in different environmental contexts within the marketplace. The memory recall of the participants might not be accurate and the test instrument is self-reported, in which case the information provided might be exaggerated. However, the test instrument has been validated in several studies and was reliably applied to similar population. The size of the warehouses, quantity of food stock, and the number of occupants in each of them were not the same, but they had certain basic similarities in their design, particularly, the absence of windows. This should have implications for ventilation but does not necessarily make the study groups nonequivalent. Therefore within the limits of the study design, the aim of the study was largely realized.

4.2. Relevance of Findings to the Field. Among the foodstuff traders who operated from the warehouses, there was evidence of significant decreases in lung volumes, which negatively impacted lung flow rates, especially forced vital capacity (FVC). Reduction in FVC is a measure of airway closure that indicates the maximum amount of airway narrowing that can possibly arise and is most serious of the pathophysiologic abnormalities in asthma [45]. This explains the significant decrease in $\mathrm{FEF}_{25-75}$ percent among traders who operated from warehouses and implies a significant limitation in airflow in peripheral/distal airways and elastic recoil of the lungs. This is consistent with obstructive pulmonary disease and explains why the decrease in PEFR was not significant. PEFR measures the patency of central airways and underestimates airflow limitations in the peripheral airways/obstructive diseases [46]. A significant decrease in $\mathrm{FEF}_{75-85}$ percent supports this conclusion. Thus, significant decrease in $\mathrm{FEV}_{1}$ of the foodstuff traders who operated from the warehouses supports the evidence of small airways diseases, which should increase the functional airways resistance. This was validated in FGDs as most of the participants complained of difficulty in breathing, choking, and chest tightness.

The significant decrease in $\mathrm{FEF}_{200-1200}$ among traders who operated from warehouses could also indicate abnormalities in the large airways or the larynx. Meanwhile, a crosssectional study revealed that exposure to dusts in steel workers was strongly associated with reductions in FVC, $\mathrm{FEV}_{1}$, and $\mathrm{FEV}_{1} / \mathrm{FVC} \%$, whereas significant reductions in $\mathrm{FEV}_{1}$ and FVC were associated with intensified occupational exposures to gases and fumes [47]. In fact, Gomes et al. [48] observed that exposure to dusts are strongly associated with decreases in forced vital capacity (FVC), $\mathrm{FEV}_{1}$, and $\mathrm{FEV}_{1} / \mathrm{FVC} \%$. Since these three measures of pulmonary function (i.e., $\mathrm{FVC}, \mathrm{FEV}_{1}$, and $\mathrm{FEV}_{1} / \mathrm{FVC} \%$ ) were significantly reduced among traders who operated from warehouses, it is plausible that they were occupationally exposed to noxious dusts, gases, and fumes. However, if it were so, then the PEFR ought to have declined significantly as well. This is reasonable, because combined occupational exposures to dusts and gases and fumes have been shown to reduce peak expiratory flow rate (PEFR) $[49,50]$. However, this study revealed that PEFR was not significantly reduced among the traders who operated from warehouses compared to those that operated from the open market. Therefore, it is plausible that the nature of pollutants in the warehouses was more of dusts than gases or fumes. This view was validated in FGDs where most of the foodstuff traders stated that they used more of inorganic chemicals (like Aldrin dusts) but also used camphor, which vaporises, and organic food preservatives (like pepper, ashes, animal droppings, etc.), all of which might produce a combination of noxious gases, fumes, and dusts. 
Considering that $\mathrm{FEV}_{1} / \mathrm{FVC} \%$ values for all foodstuff traders were above $70 \%$ cut-off point, one would have assumed that there were no airways obstruction in both groups. However, airflow obstruction may be underdiagnosed in younger people and overdiagnosed in older people if absolute cut-off values of $70 \%$ rather than "lower limits of normal (LLN)" for FEV1/FVC are used [51] and seems applicable in this instance. Therefore, allergic reactions and ventilatory impairments were evident in the foodstuff traders who operated from warehouses.

This view is further reinforced by the observation that there was a significant negative relationship between FVC, $\mathrm{FEF}_{200-1200}, \mathrm{FEF}_{25-75}, \mathrm{FEF}_{25}$, and the duration of exposure of the traders, respectively. These imply that consistent occupational exposure to inhalable noxious pollutants among foodstuff traders who operated from warehouses would progressively and adversely reduce their FVC, $\mathrm{FEF}_{200-1200}$, $\mathrm{FEF}_{25-75}$, and $\mathrm{FEF}_{25}$ values. This does not agree with the findings of Razlan et al. [35] who reported that the duration of employment did not appear to worsen the respiratory function in steel workers who were occupationally exposed to industrial dust. Similarly, Nku et al. [37] reported that there were no significant differences in the parameters of lung function between the control and the street workers, but all the mean lung function values obtained from the street workers were apparently lower than the control group. In contrast, Rao et al. [52] reported a significant decrease in $\mathrm{FEV}_{1}$ and observed that exposure to dust results in early obstructive pulmonary impairments, which further increases with increase in duration of years of exposure among rice mill workers. A similar trend was observed in this study; however the proportion of variance that accounted for the relationship between duration of exposure and indices of lung function (FVC, $\mathrm{FEF}_{200-1200}, \mathrm{FEF}_{25-75}$, and $\mathrm{FEF}_{25}$, ) varied within $14.44 \%, 12.25 \% 12.25 \%$, and $12.96 \%$, respectively. The differences in these studies might have some bearings with the nature, size, composition, and concentration of pollutants as well as ventilation at the workplace among other factors.

QTc was significantly prolonged in traders who operated from warehouses compared to traders who operated from the open market. It implied that the duration of ventricular repolarization was significantly prolonged. This study chose to focus on QTc interval to evaluate changes in repolarization morphology and duration as one of the more reliable descriptors of repolarization changes than QT duration [53]. The effect size of exposure to grain dusts on QTc among traders who operated from warehouses compared to traders who operated from open market was large $(d=1.14)$. From the etiologic perspective, the large effect size indicates a strong influence of chronic occupational exposure to grain dust and may be clinically relevant among traders who operated from warehouses. This was validated in the FGDs as most of the participants complained of palpitation and flutters. The observed change in QTc interval might be indicative of changes in ion channel functions, but the underlying complex biologic pathways are not fully delineated [54]. In contrast, responses within some hours or days after the inhalation of particles may possibly occur via pulmonary oxidative stress and systemic inflammation. This is possible, because the grain dust includes bacteria, fungi, insects, and possibly pesticide residues as well as dry plant particles. Organic dust may contain not only the grain and hay contents but also pollen, fungal spores, fungal hyphae, mycotoxins, bacteria, and endotoxins and dust from livestock pens may contain skin, hair, feathers, and excrement particles [55]. Inhalation of such grain dust may elicit reactions that are able to trigger endothelial dysfunction and a procoagulatory state with thrombus formation and promotion of atherosclerotic lesions [56]. The overall picture suggests some physiologic dysfunctions that may be adverse to health. This view is validated in FGDs where the traders who operated from warehouses stated that, within the first weeks of their work experience at the foodstuff warehouses, they experienced general feelings of malaise, low grade fever, flu-like symptoms, catarrh, headaches, sore throat, eye irritation, palpitation, dry cough, weakness, and difficulty in breathing, some of which persisted or reoccurred after relevant treatment.

4.3. Implications for Care Teams and Policymakers. The results of this should have serious health implications including consequent pulmonary and cardiac rhythm disorders in traders who operated from warehouses with preexisting cardiac malfunction that may be subjected to varied environmental pollutants at workplace. This should be of clinical concern to respiratory physiotherapists, industrial physicians, cardiologists, ergonomics, nurses, epidemiologists, community health workers, social workers, counselors, and public health authorities. This is reasonable, because more than half of the deaths due to ischemia, myocardial infarction, and cardiomyopathies are directly related to cardiac arrhythmias, which was observed in this study, and these deaths are usually sudden $[57,58]$. Myocardial substrate (myocardial damage due to coronary disease, infarction, or cardiomyopathy), the autonomic nervous system (sympathetic activation or/and parasympathetic withdrawal), and myocardial vulnerability (ventricular arrhythmias, repolarization dynamics) are believed to be key factors that contribute to the mechanism of arrhythmogenic conditions and arrhythmic death $[59,60]$ and characterize the purported "cardiac death triangle" [54]. Since the least value of QTc was observed among traders who operated from open market, it suggests that lack of proper ventilation in warehouses may have significant contributory effects on cardiac repolarization in this population. The significant positive relationship between duration of exposure to grain dust and QT supports this conclusion and implied likelihood of further deterioration in this parameter with greater duration of exposure.

Overall, the values of QTc recorded in both groups were $<440 \mathrm{~ms}$ and within normal range. Nevertheless, the findings of this study demand that relevant health authorities urgently screen this population to avert any fatal pulmonary, cardiac, or thrombotic events that are likely to arise. Therefore, public health education campaigns must be targeted at this population to ensure they understand the nature of occupational hazards at their workplace and take necessary precautions that might be required of them. This should emphasize good industrial practices to address exposure to grain dust, poor ventilation at workplace, and nonuse of face masks. 
Importantly, relevant regulatory authorities that oversight the production, marketing, and use of rodenticides/pesticides and other hazardous chemicals must ensure compliance with the required caution. The local government authorities must likewise ensure strict compliance with standard building codes to ensure proper ventilation of the warehouses for safety of the occupants. The agricultural authorities must teach the foodstuff traders the modern techniques required to preserve the market value and nutritional content of their food stock, without resorting to hazardous practices that might endanger their lives.

\section{Conclusion}

There is evidence of allergic responses, possibilities of cardiac arrhythmias, and ventilatory impairments in greater number of foodstuff traders who operated from warehouses compared to foodstuff traders who operated from open market. The warehouses lacked windows/mechanical ventilators and was deliberately designed to limit points of entry of rodents and pests. The net effect was chronic occupational exposure of the former group to a relative build-up of noxious gases, fumes, and grain dusts from foodstuff/food preservatives, rodenticides, and pesticides. The consequent health complications observed in this population emphasize the need for foodstuff traders to be enlightened on the occupational health hazards they might face at workplace. The important policy issues relevant in this context include the need to redesign foodstuff warehouses in line with standard building codes to ensure proper ventilation for users. Similarly, relevant market authorities must not permit foodstuff traders to operate from warehouses; rather they should operate from the open market, where dangers of relative build-up and chronic exposure to inhalable grain dusts are minimized.

\section{Ethical Approval}

Participants' confidentiality was maintained by using code numbers instead of names and ensuring that records were destroyed at the end of the study. They were informed of their right to withdraw from the study at any time of their choice, and these rights were strictly respected in accordance with the Helsinki declarations. This was also approved by the University of Nigeria Health Research Ethics Committee on certificate number NHREC/05/01/2008B.

\section{Consent}

Participants gave their written informed consent, prior to participation and after the purpose of the study was explained to them.

\section{Competing Interests}

The authors declare that there is no conflict of interests.

\section{Acknowledgments}

The authors wish to acknowledge the market union leaders and Enugu North Local Government Authority for all their support, permission, assistance, and contributions to the success of this work.

\section{References}

[1] S. O. Osuide and K. O. Dimuna, "None compliance with building bye-laws and regulations in nigeria-the dangers ahead," The Built Environment Journal of international Institute for Building Research (IIBR), vol. 1, no. 1, pp. 62-68, 2005.

[2] B. Lozowicka, P. Kaczynski, A. E. Paritova et al., "Pesticide residues in grain from Kazakhstan and potential health risks associated with exposure to detected pesticides," Food and Chemical Toxicology, vol. 64, pp. 238-248, 2014.

[3] A. Shoiful, H. Fujita, I. Watanabe, and K. Honda, "Concentrations of organochlorine pesticides (OCPs) residues in foodstuffs collected from traditional markets in Indonesia," Chemosphere, vol. 90, no. 5, pp. 1742-1750, 2013.

[4] M. C. P. Recena and E. D. Caldas, "Risk perception, attitudes and practices on pesticide use among farmers of a city in Midwestern Brazil," Revista de Saude Publica, vol. 42, no. 2, pp. 294-301, 2008.

[5] N. Stadlinger, A. J. Mmochi, S. Dobo, E. Gyllbäck, and L. Kumblad, "Pesticide use among smallholder rice farmers in Tanzania," Environment, Development and Sustainability, vol. 13, no. 3, pp. 641-656, 2011.

[6] G. K. Saha, Dust Allergy: Cause \& Concern, Springer, Singapore, 2016.

[7] C. Grovermann, P. Schreinemachers, and T. Berger, "Quantifying pesticide overuse from farmer and societal points of view: an application to Thailand," Crop Protection, vol. 53, pp. 161-168, 2013.

[8] C. A. Damalas, G. K. Telidis, and S. D. Thanos, "Assessing farmers' practices on disposal of pesticide waste after use," Science of the Total Environment, vol. 390, no. 2-3, pp. 341-345, 2008.

[9] K. Karunamoorthi, M. Mohammed, and F. Wassie, "Knowledge and practices of farmers with reference to pesticide management: implications on human health," Archives of Environmental \& Occupational Health, vol. 67, no. 2, pp. 109-116, 2012.

[10] M. Eddleston and M. R. Phillips, "Self poisoning with pesticides," British Medical Journal, vol. 328, no. 7430, pp. 42-44, 2004.

[11] D. Gunnell, M. Eddleston, M. R. Phillips, and F. Konradsen, "The global distribution of fatal pesticide self-poisoning: systematic review," BMC Public Health, vol. 7, article 357, 2007.

[12] T. C. Marrs, "Organophosphate poisoning," Pharmacology \& Therapeutics, vol. 58, no. 1, pp. 51-66, 1993.

[13] K. J. Donham and A. Thelin, "Health effects of agricultural pesticides," in Agricultural Medicine: Rural Occupational and Environmental Health, Safety, and Prevention, p. 205, 2016.

[14] C. Frankel and J. Watchie, "Cardiopulmonary implications of specific diseases," in Essentials of Cardiopulmonary Physical Therapy, 2016.

[15] E. Hillegass, S. T. Lowers, and E. Barker, "Cardiac muscle dysfunction and failure," Essentials of Cardiopulmonary Physical Therapy, vol. 78, 2016.

[16] S. F. Costa and B. D. Alexander, "2 Epidemiology of fungal infections: what, where, and when," Antifungal Therapy, vol. 19, article 11, 2016.

[17] M. J. Hodgson and B. Flannigan, "Occupational respiratory disease: hypersensitivity pneumo-nitis and other forms of 
interstitial lung disease," in Microorganisms in Home and Indoor Work Environments: Diversity, Health Impacts, Investigation and Control, pp. 183-203, CRC Press, Boca Raton, Fla, USA, 2016.

[18] D. C. Morrison and R. J. Ulevitch, "The effects of bacterial endotoxins on host mediation systems," The American Journal of Pathology, vol. 93, pp. 527-617, 1978.

[19] . Schafer R and C. Cuff, "Mucosa-Associated Lymphoid Tissue. Encyclopedia of Immunotoxicology," Cuff C. MucosaAssociated Lymphoid Tissue. Encyclopedia of Immunotoxicology, p. 642, 2016.

[20] D. C. Morrison and R. J. Ulevitch, "The effects of bacterial endotoxins on host mediation systems. A review," American Journal of Pathology, vol. 93, no. 2, pp. 526-617, 1978.

[21] M. E. Ogbanshi, P. U. Okechukwu, C. O. Ogbu et al., "Concentration of heavy metals and health implication of rice husk dust inhalation," World Journal of Medical Sciences, vol. 12, no. 2, pp. 132-137, 2015.

[22] R. M. Castellan, S. A. Olenchock, J. L. Hankinson et al., "Acute bronchoconstriction induced by cotton dust: doserelated responses to endotoxin and other dust factors," Annals of Internal Medicine, vol. 101, no. 2, pp. 157-163, 1984.

[23] S. M. Hashemi, R. Rostami, M. K. Hashemi, and C. A. Damalas, "Pesticide use and risk perceptions among farmers in southwest Iran," Human and Ecological Risk Assessment, vol. 18, no. 2, pp. 456-470, 2012.

[24] M. Khan, H. Z. Mahmood, and C. A. Damalas, "Pesticide use and risk perceptions among farmers in the cotton belt of Punjab, Pakistan," Crop Protection, vol. 67, no. 1, pp. 184-190, 2015.

[25] P. Van Hoi, A. P. J. Mol, P. Oosterveer, and P. J. van den Brink, "Pesticide distribution and use in vegetable production in the red river delta of Vietnam," Renewable Agriculture and Food Systems, vol. 24, no. 3, pp. 174-185, 2009.

[26] B. Cushen, I. Sulaiman, N. Donoghue et al., "High prevalence of obstructive lung disease in non-smoking farmers: the Irish farmers lung health study," Respiratory Medicine, vol. 115, pp. 1319, 2016.

[27] J. Pepys, "Hypersensitivity diseases of the lungs due to fungi and organic dusts," Monographs in Allergy, vol. 4, pp. 1-147, 1969.

[28] D. Flaherty, P. Bhansali, and N. Chavaje, "Grain fever syndrome induced by inhalation of airborne grain dust," Journal of Allergy and Clinical Immunology, vol. 69, no. 5, pp. 435-443, 1982.

[29] J. A. Dosman, D. J. Cotton, B. L. Graham, K. Y. Robert Li, F. Froh, and G. D. Barnett, "Chronic bronchitis and decreased forced expiratory flow rates in lifetime nonsmoking grain workers 13," American Review of Respiratory Disease, vol. 121, no. 1, pp. 11-16, 1980.

[30] M. Chan-Yeung, R. Wong, and L. MacLean, "Respiratory abnormalities among grain elevator workers," Chest, vol. 75, no. 4, pp. 461-467, 1979.

[31] W. Alakija, V. I. Iyawe, L. N. Jarikre, and J. C. Chiwuzie, "Ventilatory function of workers at Okpella cement factory in Nigeria," West African Journal of Medicine, vol. 9, no. 3, pp. 187192,1990 .

[32] NIOSH Division of Respiratory Studies Initial Questionnaire of the NIOSH Occupational Asthma Identification Project (OAID), February 2012, https://www.cdc.gov/niosh/pdfs/79116-h.pdf.

[33] G. L. Delclos, A. A. Arif, L. Aday et al., "Validation of an asthma questionnaire for use in healthcare workers," Occupational and Environmental Medicine, vol. 63, no. 3, pp. 173-179, 2006.
[34] B. R. Celli, W. MacNee, A. Agusti et al., "Standards for the diagnosis and treatment of patients with COPD: a summary of the ATS/ERS position paper," European Respiratory Journal, vol. 23, no. 6, pp. 932-946, 2004.

[35] M. Razlan, L. Naing, A. Zulkifli, and Y. Kamarul, "Respiratory health of rice millers in Kelantan, Malaysia," The Southeast Asian Journal of Tropical Medicine and Public Health, vol. 3, pp. 575$578,2000$.

[36] N. S. Mostafa, M. A. Abdel-Hamid, and L. S. AlBagoury, "Workrelated respiratory disorders among street sweepers in Cairo, Egypt, a comparative study," Egyptian Journal of Community Medicine, vol. 33, no. 2, 2015.

[37] C. O. Nku, E. J. Peters, A. 1. Estiet, O. Oku, and E. E. Osim, "Lung function, oxygen saturation and symptoms among street sweepers in calabar-Nigeria," Nigerian Journal of Physiological Sciences, vol. 20, no. 1-2, pp. 79-84, 2005.

[38] M. A. Hossain and L. N. Islam, "Effect of occupational exposure on allergic diseases and relationship with serum IgE levels in the tannery workers in Bangladesh," Bioresearch Communications, vol. 2, no. 1, pp. 158-163, 2016.

[39] X. R. Bonnefoy, I. Annesi-Maesano, L. Moreno et al., Review of Evidence on Housing and Health, World Health Organization Europe, Budapest, Hungary, 2004.

[40] C. Tischer, C.-M. Chen, and J. Heinrich, "Association between domestic mould and mould components, and asthma and allergy in children: a systematic review," European Respiratory Journal, vol. 38, no. 4, pp. 812-824, 2011.

[41] M. Frankel, G. Bekö, M. Timm, S. Gustavsen, E. W. Hansen, and A. M. Madsen, "Seasonal variations of indoor microbial exposures and their relation to temperature, relative humidity, and air exchange rate," Applied and Environmental Microbiology, vol. 78, no. 23, pp. 8289-8297, 2012.

[42] N. N. Jibiri and S. T. Obarhua, "Indoor and outdoor Gamma dose rate exposure levels in major commercial building material distribution outlets and their radiological implication and occupant in Ibadan, Nigeria," Journal of Natural Sciences Research, vol. 3, no. 3, pp. 25-31, 2013.

[43] S. O. Izomoh and J. I. Olomu, "The effects of poor architectural design and poor application of appropriate technology on the health of the occupants of residential buildings (Nigerian Situation)," The Built Environment Journal of International Institute for Building Research (IIBR), vol. 1, no. 1, p. 3, 2005.

[44] J. E. Ahianba, K. O. Dimuna, and G. R. Okogun, "Built environment decay and urban health in Nigeria," Journal of Human Ecology, vol. 23, no. 3, pp. 259-265, 2008.

[45] P. T. Macklem, "The physiology of small airways," American Journal of Respiratory and Critical Care Medicine, vol. 157, no. 5, pp. S181-S183, 1998.

[46] M. L. Levy, "Is spirometry essential in diagnosing asthma? No," British Journal of General Practice, vol. 66, no. 650, p. 485, 2016.

[47] X. Xu, D. C. Christiani, D. W. Dockery, and L. Wang, "Exposureresponse relationships between occupational exposures and chronic respiratory illness: a community-based study," American Review of Respiratory Disease, vol. 146, no. 2, pp. 413-418, 1992.

[48] J. Gomes, O. L. Lloyd, N. J. Norman, and P. Pahwa, "Dust exposure and impairment of lung function at a small iron foundry in a rapidly developing country," Occupational and Environmental Medicine, vol. 58, no. 10, pp. 656-662, 2001.

[49] M.-L. Wang, L. McCabe, J. L. Hankinson et al., "Longitudinal and cross-sectional analyses of lung function in steelworkers," 
American Journal of Respiratory and Critical Care Medicine, vol. 153, no. 6, pp. 1907-1913, 1996.

[50] Q. T. Pham, G. Mastrangelo, N. Chau, and J. Haluszka, "Five year longitudinal comparison of respiratory symptoms and function in steelworkers and unexposed workers," Clinical Respiratory Physiology, vol. 15, no. 3, pp. 469-480, 1979.

[51] M. R. Miller and M. L. Levy, "Chronic obstructive pulmonary disease: missed diagnosis versus misdiagnosis," BMJ, vol. 351, Article ID h3021, 2015.

[52] N. M. Rao, H. N. Saiyed, S. K. Kashyap, and S. K. Chatterjee, "Airway obstruction in silicosis workers," Lung India, no. 4, pp. 126-129, 1991.

[53] P. M. Okin, J. T. Wright, M. S. Nieminen et al., "Ethnic differences in electrocardiographic criteria for left ventricular hypertrophy: the LIFE study," American Journal of Hypertension, vol. 15, no. 8, pp. 663-671, 2002.

[54] A. Henneberger, W. Zareba, A. Ibald-Mulli et al., "Repolarization changes induced by air pollution in ischemic heart disease patients," Environmental Health Perspectives, vol. 113, no. 4, pp. 440-446, 2005.

[55] The Swedish National Board of Occupational Safety and Health, "Organic Dust in Agriculture. General Recommendations of the Swedish National Board of Occupational Safety and Health on Organic Dust in Agriculture," AFS: 11, 1994.

[56] K. Donaldson, V. Stone, A. Seaton, and W. MacNee, "Ambient particle inhalation and the cardiovascular system: potential mechanisms," Environmental Health Perspectives, vol. 109, supplement 4, pp. 523-527, 2001.

[57] S. S. Chugh, K. Reinier, C. Teodorescu et al., "Epidemiology of sudden cardiac death: clinical and research implications," Progress in Cardiovascular Diseases, vol. 51, no. 3, pp. 213-228, 2008.

[58] P. M. Spooner, C. Albert, E. J. Benjamin et al., "Sudden cardiac death, genes, and arrhythmogenesis: consideration of new population and mechanistic approaches from a National Heart, Lung, and Blood Institute Workshop, part II," Circulation, vol. 103, no. 20, pp. 2447-2452, 2001.

[59] W. Zareba, J. P. Couderc, G. Oberdörster et al., "ECG parameters and exposure to carbon ultrafine particles in young healthy subjects," Inhalation Toxicology, vol. 21, no. 3, pp. 223-233, 2009.

[60] W. Zareba, A. Nomura, and J. P. Couderc, "Cardiovascular effects of air pollution: what to measure in ECG?" Environmental Health Perspectives, vol. 109, no. 4, pp. 533-538, 2001. 


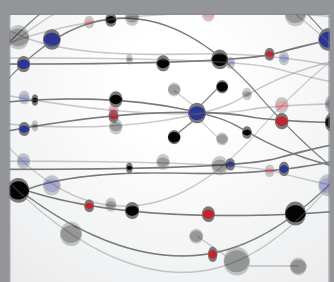

The Scientific World Journal
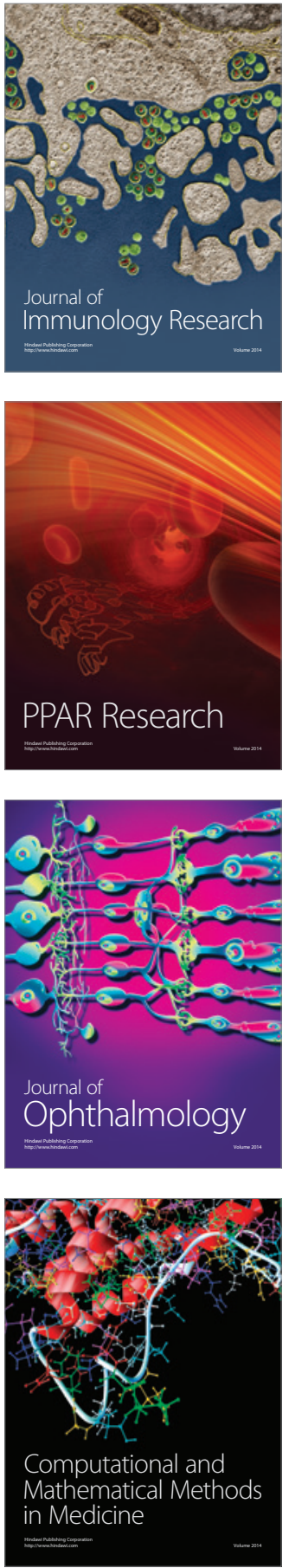

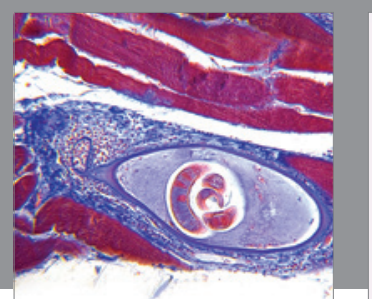

Gastroenterology Research and Practice

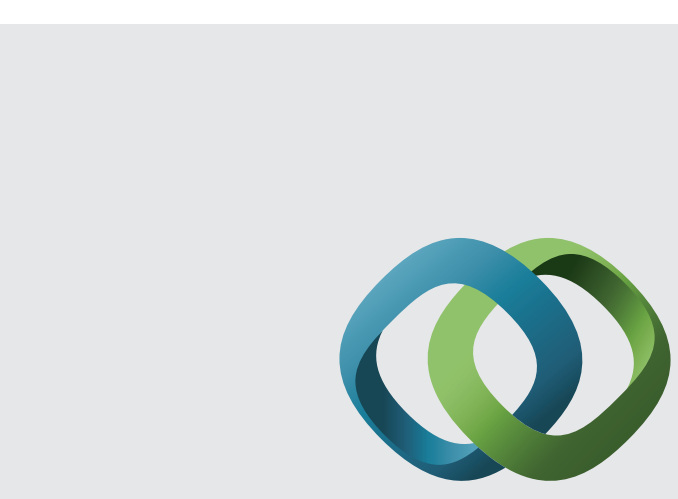

\section{Hindawi}

Submit your manuscripts at

http://www.hindawi.com
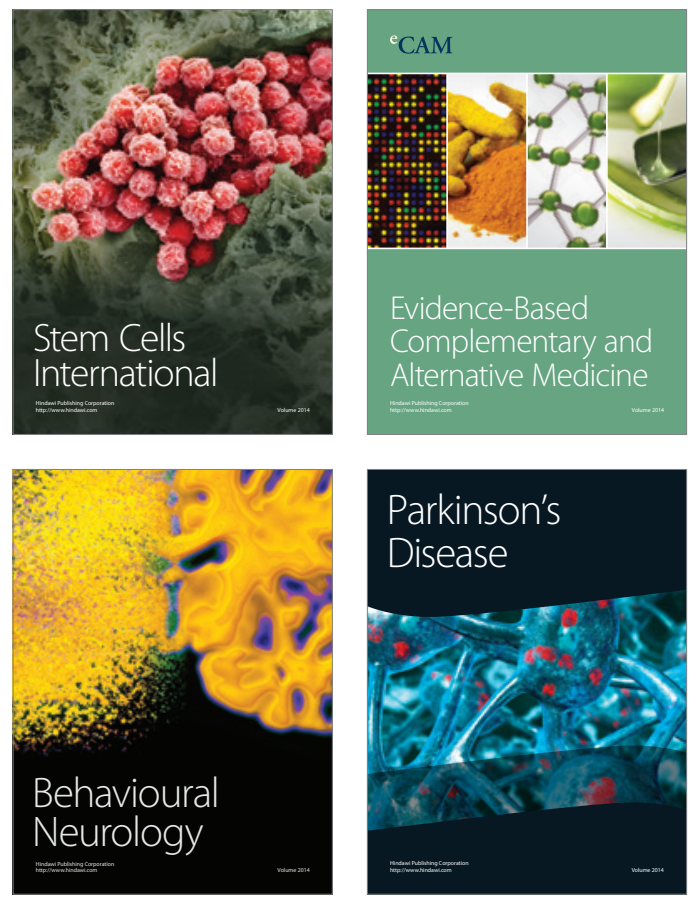
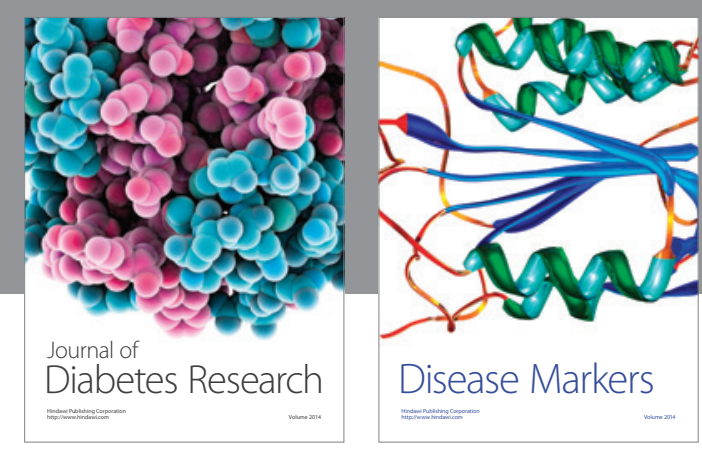

Disease Markers
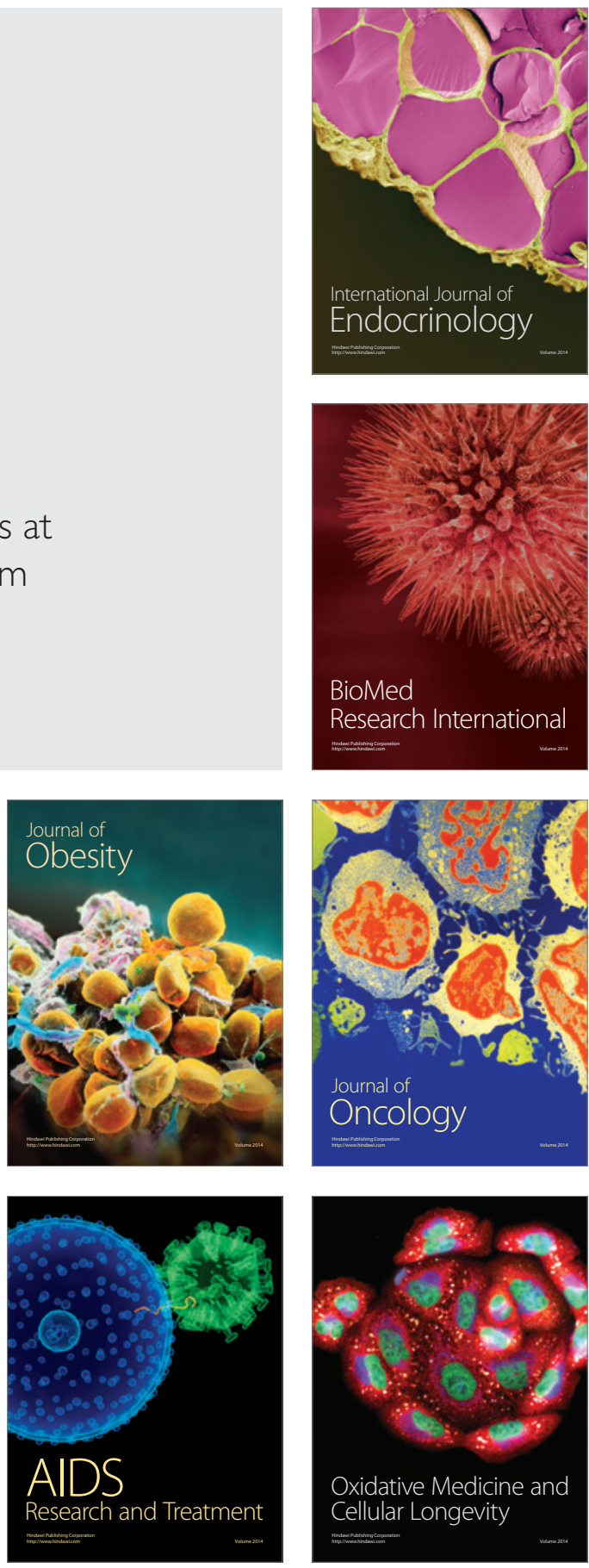